\title{
Mechanisms of Vasculitis: How Pauci-Immune Is ANCA-Associated Renal Vasculitis?
}

\author{
P. van Paassen ${ }^{a} \quad$ J.W. Cohen Tervaert ${ }^{a} \quad$ P. Heeringa ${ }^{b}$ \\ a Department of Clinical and Experimental Immunology, Cardiovascular Research Institute Maastricht, \\ University Maastricht, Maastricht, ${ }^{b}$ Department of Pathology and Laboratory Medicine, Medical Biology Section, \\ University of Groningen, Groningen, The Netherlands
}

\section{Key Words}

Vasculitis $\cdot$ Renal vasculitis $\cdot$ ANCA-associated renal

vasculitis $\cdot$ Glomerulonephritis $\cdot$ Anti-neutrophil

cytoplasmic antibody $\cdot$ Neutrophil

\begin{abstract}
Both the innate and the acquired immune system are involved in the pathophysiology of renal vasculitis. However, anti-neutrophil cytoplasmic antibody (ANCA)-associated renal vasculitis is characterized by a 'pauci-immune' pattern of immunofluorescence during kidney biopsy, indicating the relative lack of immunoglobulin and complement deposition within the kidney. On the other hand, evidence is accumulating that ANCA, autoantibodies against constituents of primary granules of neutrophils and the lysosomes of monocytes, play a pathogenic role in renal vasculitis. In this review we will discuss both in vitro and in vivo experimental data providing compelling evidence that ANCA are a primary pathogenic factor in renal vasculitis, mainly by augmenting leukocyte-endothelial interactions. We will also address novel data, pointing at the role of, in addition to ANCA, nonspecific proinflammatory signals. Finally, we propose a working hypothesis of the pathogenesis of ANCA-associated renal vasculitis.

Copyright $\odot 2007$ S. Karger AG, Basel
\end{abstract}

\section{Introduction}

Vasculitis is a pathological process characterized by inflammation and necrosis of blood vessel walls. The vasculitic process can affect vessels of any type, size or location and therefore can cause damage and dysfunction in virtually any organ system. In the kidney, vasculitis preferentially affects the small vessels (arterioles, capillaries, venules) [1]. In patients with systemic vasculitis, involvement of the kidney has great impact on prognosis and choice of therapy but may be discovered relatively late in the disease course, particularly when symptoms of systemic disease are lacking. Microscopic hematuria with or without proteinuria is consistent with renal vasculitis. Renal function may be well preserved in the early phase whereas rapid deterioration of renal function is an ominous sign mandating prompt diagnosis and initiation of therapy. Microvascular inflammation and focal segmental fibrinoid necrosis with extracapillary proliferation and crescent formation is the histopathological hallmark of disease [2].

In the pathophysiology of renal vasculitis, both the innate and the acquired immune system are involved. Based on immunofluorescence studies of kidney biopsies, three patterns are found [3]. First, an immune complex-medi-

\section{KARGER}

Fax +4161306 1234 E-Mail karger@karger.ch www.karger.com
P. van Paassen

Department of Clinical and Experimental Immunology

University Hospital Maastricht, PO Box 5800

NL-6202 AZ Maastricht (The Netherlands)

Tel. +31 43388 1433, Fax +31 43388 4164, E-Mail p.vanpaassen@immuno.unimaas.nl 
Table 1. Characteristics of ANCA-associated vasculitides

\begin{tabular}{lllc}
\hline Disease & Clinical & Percentage of patients \\
\cline { 3 - 4 } & & MPO-ANCA & Pr3-ANCA \\
\hline Churg-Strauss syndrome & Asthma, eosinophilia, neuropathy, nephritis & $30-70$ & $<10$ \\
Wegener's granulomatosis & Nose bleeds, nephritis, lung lesions & $10-30$ & $>70$ \\
Microscopic polyangiitis & Nephritis, alveolar lung hemorrhage, purpura & $30-70$ & $10-30$ \\
Renal limited vasculitis & Nephritis & $30-70$ & $10-30$ \\
\hline
\end{tabular}

ated pattern such as in Henoch-Schönlein purpura, cryoglobulinemic vasculitis and systemic lupus erythematosus nephritis. Second, a linear fluorescence pattern due to a direct antibody-mediated attack such as in anti-glomerular basement membrane (GBM) disease. Third, the so-called 'pauci-immune' pattern that is strongly associated with the presence of anti-neutrophil cytoplasmic autoantibodies (ANCA). Pauci-immune indicates the relative lack of immunoglobulin and complement deposition within the kidney as demonstrated by indirect immunofluorescence techniques. ANCA-associated vasculitides consist of four separate syndromes: Wegener's granulomatosis, microscopic polyangiitis, Churg-Strauss syndrome, and renal limited vasculitis. The primary antigenic targets of ANCA are the lysosomal enzymes myeloperoxidase (MPO-ANCA) and proteinase 3 (Pr3-ANCA), although other target antigens, e.g. human lysosomal-associated membrane protein 2 (h-LAMP-2) [4], have been described [5]. ANCA are quite frequently but not always found in these forms of vasculitis. The type of ANCA (MPO or Pr3) correlates well, but not exactly, with the clinical picture (table 1). However, in cases where there is renal involvement, ANCA is present almost invariably [6].

The strong association of rises in elevated ANCA titers and disease reactivation suggests a pivotal pathogenic role of these autoantibodies in renal vasculitis [7]. The recent description of a case in which transfer of maternal ANCA during pregnancy resulted in pulmonary hemorrhage and impaired renal function in a newborn within $48 \mathrm{~h}$ after delivery further substantiates the immunopathogenic and causative role of ANCA in a human model [8]. We will briefly summarize the evidence obtained from in vitro and in vivo studies that ANCA are indeed an important factor in ANCA-associated renal vasculitis.

\section{Pathophysiological Mechanisms}

\section{In vitro}

ANCA are directed against constituents of the primary granules of neutrophils and the lysosomes of monocytes [5]. This can be either Pr3, a 29-kDa neutral serine protease, or MPO, a $140-\mathrm{kDa}$ enzyme involved in the generation of reactive oxygen species. ANCA that recognize Pr3 produce a characteristic granular cytoplasmic staining pattern on ethanol-fixed granulocytes when detected by a standard indirect immunofluorescence technique (c-ANCA). ANCA that react with MPO, on the other hand, produce a perinuclear staining pattern (PANCA).

The in vitro evidence that these autoantibodies induce or sustain vascular inflammation, either directly or indirectly, is firm and has been reviewed in many reports. [for recent reviews, see 9,10$]$.

The key event appears to be the activation of neutrophils by ANCA [11]. This results in the generation of reactive oxygen intermediates, derived from superoxide anion, degranulation with extracellular release of lysosomal enzymes, such as elastase, metalloproteases and including the ANCA antigens themselves [12]. These neutrophil-derived products confer toxicity for endothelial cells and tissue constituents [13]. Moreover, ANCA induce increased neutrophil cytokine production, such as interleukin (IL)-1 $\beta$, which further stimulates local inflammatory processes [11].

The neutrophil response itself is greatly enhanced by minor (pro)inflammatory stimuli, such as TNF- $\alpha$, that prime the interaction between ANCA and the neutrophil [11]. In vivo, these proinflammatory stimuli may for instance be induced by preceding or concomitant infectious agents. In the primed neutrophil, the ANCA antigens, Pr3 and MPO, translocate to the cell surface, facilitating the binding to ANCA. Binding of the $\mathrm{F}\left(\mathrm{ab}^{\prime}\right)_{2}$ portion of ANCA IgG with these ANCA antigens and si- 
multaneous interaction between the Fc part of ANCA IgG and Fc $\gamma$ receptors on the same cell or on neighboring neutrophils triggers the signaling cascade leading to further neutrophil activation. It is suggested that other, nonFc $\gamma$ R-mediated neutrophil membrane cofactors are used as well by ANCA, but these have not been identified yet [14].

Signaling pathways thus far identified to be involved in neutrophil activation include p38 mitogen-activated protein kinase (MAPK), extracellular signal-regulated kinase as well as phosphatidylinositol-3 kinase control systems [15-17]. Recently, Hewins et al. [18] reported that IL-18 is expressed in kidneys of patients with ANCAassociated glomerulonephritis, and that IL-18 primes neutrophils, via p38MAPK, for increased superoxide production in response to ANCA. Interestingly, the ANCA-induced superoxide production in IL-18-primed neutrophils was not affected by anti-TNF- $\alpha$ antibody treatment, suggesting a direct effect of IL-18 on priming neutrophil oxygen radical production [18]. Since IL-18 is best known for its role in polarization of naïve $T$ cells to a Th1 response with subsequent production of interferon- $\gamma$ [19], the observations by Hewins et al. [18] also suggest an involvement of Th1-mediated responses in ANCA-associated diseases, but this remains to be established.

Interestingly, ANCA also appear to interact with the cell surface of apoptotic neutrophils with subsequent opsonization of these cells, thereby modulating the release of proinflammatory mediators by macrophages [20]. In addition, ANCA have been shown to enhance the neutrophil adherence to endothelial monolayers, whereas coincubation of ANCA-activated neutrophils and endothelial cells induces endothelial cell lysis, via the CD11/CD18 integrin pathway $[13,21]$. The adherence of these locally activated neutrophils is crucial for subsequent injury to endothelial cells and destruction of underlying tissue.

In vivo

Although in vitro data suggest a pathogenic role of ANCA in (renal) vasculitis, in vivo data are required to support the concept.

The term 'pauci-immune' used as an eponym for ANCA-associated vasculitis in a sense is confusing considering the presence of these autoantibodies in the blood, the influx of innate immune cells, and the severe damage that occurs to the glomerular capillary wall. Although indeed immune complexes (ICX), containing IgG or IgA, are generally lacking in the classic lesions of ANCA-associated glomerulonephritis, non-specific IgM deposits and certainly complement deposition are often present, suggesting prior ICX deposition [22].

Induction of MPO-ANCA in Brown-Norway rats immunized with human MPO did not appear to induce renal vasculitis [23]. However, unilateral perfusion of the left kidney with a neutrophil extract, containing MPO, and hydrogen peroxide $\left(\mathrm{H}_{2} \mathrm{O}_{2}\right)$, induced severe necrotizing crescentic glomerulonephritis only in MPO-immunized Brown-Norway rats and no lesions in the non-immunized control rats. Most interestingly, ICX deposits were observed in the kidney shortly after perfusion, but these ICX appeared to have dissolved already at the time that renal damage was at its peak. Using a similar approach, Yang et al. [24] observed that the degree of histological injury correlated with the amount of glomerular IgG immune deposits and concluded that this perfusion rat model is an example of ICX-mediated glomerulonephritis.

The contention that some kind of ICX deposition, even other than ANCA along the glomerular capillary wall, enhances local immune responses was further supported by the finding that MPO-immunized rats injected with anti-GBM antibodies, in a dose as low that anti-GBM itself did not induce glomerulonephritis, developed severe necrotic lesions in the kidney whereas this did not happen in non-immunized rats [25].

In these rat models the role of ANCA could still be interpreted as coincidental, but over the last years new and elegant experiments have further corroborated the in vivo' pathogenic implications of ANCA in renal vasculitis. Xiao et al. [26] immunized MPO-deficient mice with murine MPO, creating development of circulating antiMPO antibodies in these mice. Then, along two lines of evidence they showed that ANCA induces glomerulonephritis. First, adoptive transfer of splenocytes from murine MPO-immunized MPO-deficient mice into recombinase activating gene knockout $\left(\mathrm{RAG}^{-/-}\right.$) mice that lack functioning $\mathrm{B}$ and $\mathrm{T}$ lymphocytes induced circulating anti-MPO antibodies in the recipient mice. This was accompanied by the development of severe renal lesions characterized by invasion of inflammatory cells and fibrin within Bowman's space resulting in the formation of crescents. Second, intravenous injection of purified antiMPO IgG into RAG2 ${ }^{-/-}$mice or wild-type mice also, although in a milder form, induced focal necrotizing crescentic glomerulonephritis, closely resembling the picture in human disease, with typical paucity of immune reactants (complement and Igs), at least in the later phase of glomerular disease. These data strongly suggest that ANCA, even without clear participation of T or B lymphocytes, can induce vasculitis. 
Recent studies by Little et al. [27] provide additional support for the in vivo pathogenic potential of MPOANCA. Upon immunization with human MPO, WKY rats developed anti-human MPO antibodies that were cross-reactive with rat MPO and 6 weeks after immunization a substantial number of rats had developed pauciimmune necrotizing crescentic glomerulonephritis and pulmonary capillaritis. By intravital microscopy, MPOANCA-rich IgG was found to enhance leukocyte-endothelial interactions elicited by proinflammatory stimuli leading to post-capillary venular hemorrhage.

In contrast to the in vivo models of MPO-ANCA-mediated vasculitis/glomerulonephritis, development of an animal model for Pr3-ANCA-mediated vasculitis has proven to be more difficult. In the mouse, anti-Pr3 antibodies elicited by immunization of Pr3/elastase-deficient mice with recombinant murine $\operatorname{Pr} 3$ did not appear to be pathogenic by themselves but did enhance TNF- $\alpha$-induced local inflammatory responses [28]. These observations suggest functional and pathogenic differences between MPO- and Pr3-ANCA, as has been suggested to be present in patients as well [29]. The mechanisms underlying these differences are not well understood. It is, however, important to emphasize that the physical and structural characteristics of the ANCA target antigens, MPO and Pr3, are very different [28]. MPO is a highly cationic $140-\mathrm{kDa}$ homodimer with a theoretical isoelectric point (pI) of 10.2 whereas $\operatorname{Pr} 3$ is a $30-\mathrm{kDa}$ protein with a theoretical pI of 7.7 [28]. These physical differences lead to differential interactions with negatively charged proteoglycans and extracellular matrix components in the kidney as has been demonstrated by renal perfusion studies in rats $[30,31]$. In addition, released MPO and Pr3 do not only bind to the surface of endothelial cells but are also internalized by these cells where they exert differential effects [32]. For example, internalization of $\operatorname{Pr} 3$ causes endothelial cell apoptosis whereas internalization of MPO induces the generation of oxygen radicals [32]. Thus, differences in clinical and pathological expression of disease between MPO- and Pr3-ANCA may be influenced by antigen dependent effects on the endothelium.

The experimental animal models are powerful tools to further explore the hypotheses that arise from both clinical observations and in vitro data in an in vivo setting. Huugen et al. [33] thus recently tested the hypothesis, derived from clinical experience, that besides ANCA, a second (non-specific) proinflammatory signal is necessary to induce more severe disease. Indeed, systemic administration of bacterial lipopolysaccharide (LPS) as proinflammatory stimulus dose-dependently increased renal injury (glomerular crescent formation and necrosis) induced by concomitant anti-MPO IgG. In the early phase, as expected, accumulation of neutrophils occurred and these cells were found to be the main effector cells in disease induction [34]. Also, LPS induced a transient increase in TNF- $\alpha$, together with a rise in circulating MPO levels. However, anti-TNF- $\alpha$ treatment by a single intraperitoneal injection of anti-murine TNF- $\alpha$ antibody TN3 attenuated, but did not prevent, the LPS-mediated aggravation of anti-MPO IgG-induced glomerulonephritis. Recent, preliminary data from this model indicate an unexpected but crucial role for the alternative pathway of complement activation in disease induction [abstract: Xiao et al., Kidney Blood Press Res 2005;28:159] and suggest that targeting complement factor $\mathrm{C} 5$ is a potential therapeutic option in MPO-ANCA-mediated glomerulonephritis [abstract: Huugen et al., J Am Soc Nephrol 2005; 16(suppl):30]. Clearly, these preliminary observations require further studies.

\section{T Cells}

The fact that ANCA are predominantly of the IgG isotype and that isotype switching is dependent on T-helper cells indicates that $\mathrm{T}$ lymphocytes must be involved in the onset of the autoimmune response. However, whether $\mathrm{T}$ cells also play a role in the effector phase of the disease is still a matter of debate. In the mouse, anti-MPO-mediated necrotizing crescentic glomerulonephritis can be induced in mice that lack functioning $\mathrm{T}$ and $\mathrm{B}$ cells and by anti-MPO antibodies alone [26]. Both observations demonstrate that antigen-specific $\mathrm{T}$ cells are not required for the induction of acute injury but they do not exclude a role for T cells in the later stages of the disease. Normally, acute injury is followed by a chronic inflammatory phase that is governed by macrophages and $\mathrm{T}$ cells and often leads to fibrosis. However, this late phase of injury in ANCA-associated vasculitides and the role of $\mathrm{T}$ cells therein have not been extensively studied.

The evidence that $\mathrm{T}$-cell responses are altered in ANCA-associated vasculitides is firm and has recently been extensively reviewed [35]. In patients with ANCAassociated vasculitis, activated circulating $\mathrm{T}$ cells with a Th1 cytokine profile have been demonstrated during active disease as well as during remission [36, 37]. In addition, $\mathrm{T}$ cells derived from granulomatous tissue of Wegener granulomatosis patients also display a Th1 cytokine profile [38]. Of particular interest are recent observations showing expanded populations of $\mathrm{CD}^{+}$ 
Fig. 1. Working hypothesis for the pathogenesis of ANCA-associated vasculitis. Proinflammatory cytokines and chemokines, e.g. TNF- $\alpha$, released due to local or systemic infection cause upregulation of endothelial adhesion molecules (e.g. selectins, ICAM-1, and VCAM) and prime the neutrophil. Neutrophil priming causes upregulation of neutrophil adhesion molecules (CD11b) and translocation of the ANCA antigens from their lysosomal compartments to the cell surface. Engagement of the $\mathrm{F}\left(\mathrm{ab}^{\prime}\right)_{2}$ portion of ANCA with ANCA antigens on the cell surface and interaction of the Fc part of the antibody with $\mathrm{Fc}$ receptors activates the neutrophil causing increased neutrophil-vessel wall adherence and transmigration. ANCAmediated neutrophil activation also triggers reactive oxygen radical production and causes degranulation resulting in the release of lysosomal enzymes including the ANCA antigens MPO and Pr3. Released MPO and Pr3 bind to endothelial cells and extracellular matrix proteins which, in the presence of ANCA, results in transient in situ immune complex (IXC) formation. These locally formed ICX together with $\mathrm{C} 5 \mathrm{a}$ generation via activation of the alternative pathway (AP) of complement activation amplify the inflammatory response by enhancing neutrophil recruitment. Ultimately, necrotizing vasculitis develops [figure adapted from 9 , with permission].

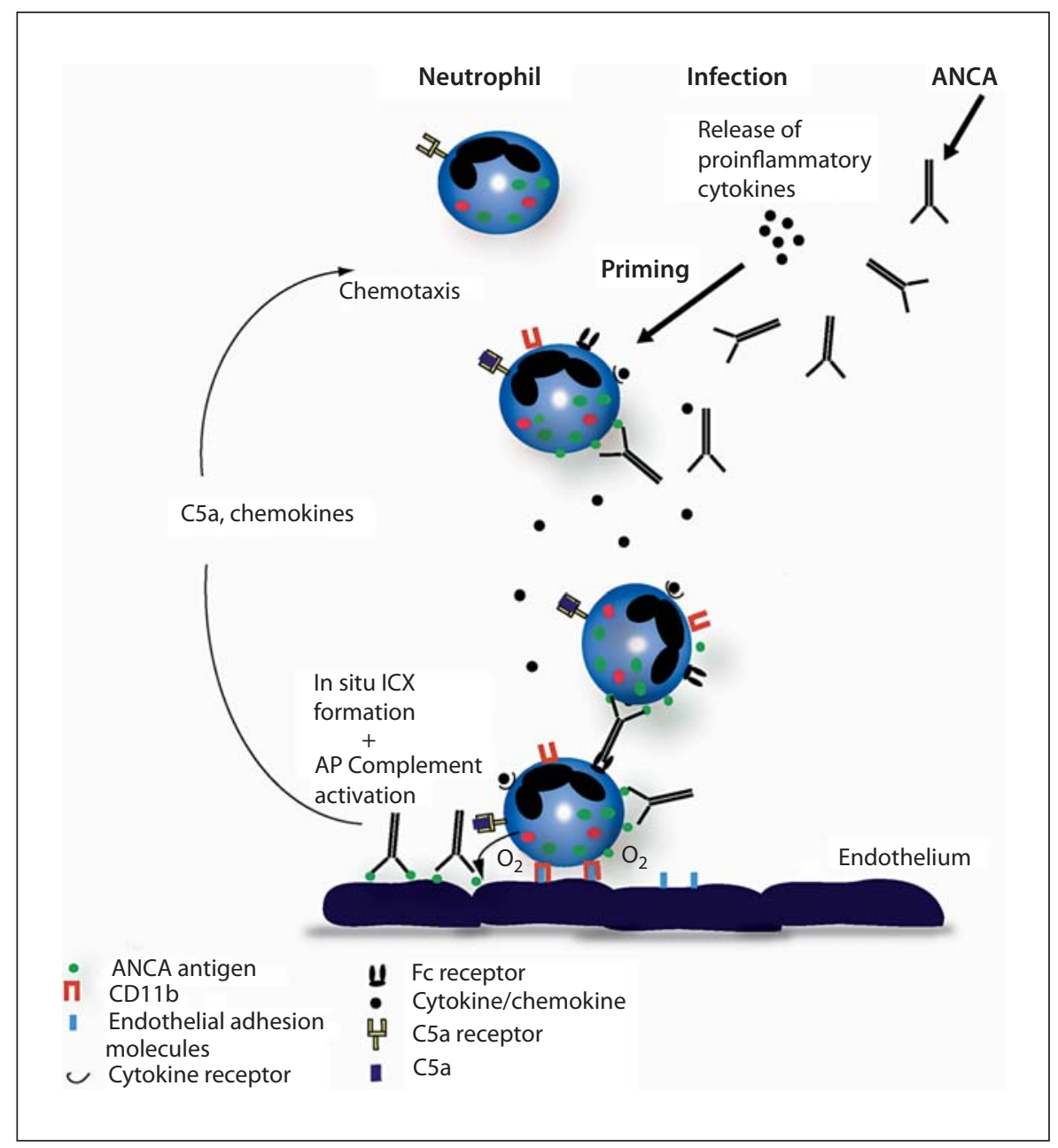

and $\mathrm{CD}^{+} \mathrm{T}$ cells that lack the expression of the costimulatory molecule CD28 in peripheral blood of Wegener granulomatosis patients that correlated with more severe disease manifestations [39]. $\mathrm{CD} 4^{+} \mathrm{CD} 28^{-} \mathrm{T}$ cells have also been detected in granulomas and appear to contribute to IFN- $\gamma$ and TNF- $\alpha$ production [40]. The main question, however, remains whether the observed $\mathrm{T}$-cell responses are ANCA antigen-specific. So far, results from studies attempting to identify MPO and Pr3-reactive T cells in patients with vasculitis are inconsistent and have revealed that such cells can occur in normal individuals as well $[41,42]$. These observations suggest that antigens other than MPO and Pr3 may be involved in driving the aberrant T-cell responses in ANCA-associated vasculitides as well. In this respect, proteins of Staphylococcus aureus which show homology with human Pr3 are potential candidates $[43,44]$.

\section{A Working Hypothesis for the Pathogenesis of ANCA-Associated Vasculitis (fig. 1)}

We derive our current working hypothesis from the experimental data described above. In this hypothesis, ANCA and proinflammatory stimuli of infectious origin synergize in causing necrotizing vasculitis. Proinflammatory signals promote the adhesion of neutrophils to the endothelium and cause translocation of the ANCA antigens to the neutrophil cell surface enabling their interaction with ANCA. Binding of ANCA to primed neutrophils induces activation of these cells resulting in oxygen radical production and the release of lysosomal enzymes including the ANCA antigens themselves. Because of their cationic nature, released MPO and Pr3 will bind to the surface of endothelial cells and tissue matrix resulting in small amounts of in situ ICX formation. The ICX deposits are most likely transient because they will en- 
hance further recruitment and activation of neutrophils that in turn attack and dissolve these focally formed ICX. The in situ formed ICX initiate and sustain an innate inflammatory amplification loop that probably also involves activation of the alternative pathway of the complement system. Ultimately, necrotizing vascular injury develops.

The recently developed animal models for ANCA-mediated vasculitis together with ongoing clinical and in vitro studies will be very helpful in testing the working hypothesis. In the end, the knowledge gained will be essential to develop less toxic and more specific treatment modalities for this severe disease.

\section{Acknowledgements}

Supported by a grant from the Dutch Kidney Foundation (C01.1927 J.W. Cohen Tervaert, P. Heeringa). P. Heeringa is supported by a grant from The Netherlands Organization for Scientific Research (NWO VIDI grant 917.66.341).

\section{References}

1 Falk RJ, Jennette JC: ANCA small-vessel vasculitis. J Am Soc Nephrol 1997;8:314-322.

2 Jennette JC: Antineutrophil cytoplasmic autoantibody-associated diseases: a pathologist's perspective. Am J Kidney Dis 1991;18: 164-170.

-3 Jennette JC: Rapidly progressive crescentic glomerulonephritis. Kidney Int 2003;63: 1164-1177.

-4 Kain R, Matsui K, Exner M, Binder S, Schaffner G, Sommer EM, Kerjaschki D: A novel class of autoantigens of anti-neutrophil cytoplasmic antibodies in necrotizing and crescentic glomerulonephritis: the lysosomal membrane glycoprotein h-lamp-2 in neutrophil granulocytes and a related membrane protein in glomerular endothelial cells. J Exp Med 1995;181:585-597.

-5 Kallenberg CG, Brouwer E, Weening JJ, Tervaert JW: Anti-neutrophil cytoplasmic antibodies: current diagnostic and pathophysiological potential. Kidney Int 1994;46:1-15.

-6 Tervaert JW, Goldschmeding R, Elema JD, van der Giessen M, Huitema MG, van der Hem GK, The TH, dem Borne AE, Kallenberg CG: Autoantibodies against myeloid lysosomal enzymes in crescentic glomerulonephritis. Kidney Int 1990;37:799-806.

7 Tervaert JW, Huitema MG, Hene RJ, Sluiter WJ, The TH, van der Hem GK, Kallenberg CG: Prevention of relapses in Wegener's granulomatosis by treatment based on antineutrophil cytoplasmic antibody titre. Lancet 1990;336:709-711.

$\checkmark 8$ Bansal PJ, Tobin MC: Neonatal microscopic polyangiitis secondary to transfer of maternal myeloperoxidase-antineutrophil cytoplasmic antibody resulting in neonatal pulmonary hemorrhage and renal involvement. Ann Allergy Asthma Immunol 2004;93: 398-401.

-9 Heeringa P, Huugen D, Tervaert JW: Antineutrophil cytoplasmic autoantibodies and leukocyte-endothelial interactions: a sticky connection? Trends Immunol 2005;26:561564.

How Pauci-Immune Is ANCA-Associated Renal Vasculitis?
10 Jennette JC, Xiao H, Falk RJ: Pathogenesis of vascular inflammation by anti-neutrophil cytoplasmic antibodies. J Am Soc Nephrol 2006; 17:1235-1242.

11 Rarok AA, Limburg PC, Kallenberg CG: Neutrophil-activating potential of antineutrophil cytoplasm autoantibodies. J Leukoc Biol 2003;74:3-15.

12 Charles LA, Caldas ML, Falk RJ, Terrell RS, Jennette JC: Antibodies against granule proteins activate neutrophils in vitro. J Leukoc Biol 1991;50:539-546.

13 Savage CO, Pottinger BE, Gaskin G, Pusey CD, Pearson JD: Autoantibodies developing to myeloperoxidase and proteinase 3 in systemic vasculitis stimulate neutrophil cytotoxicity toward cultured endothelial cells. Am J Pathol 1992;141:335-342.

14 Williams JM, Ben Smith A, Hewins P, Dove SK, Hughes P, McEwan R, Wakelam MJ, Savage CO: Activation of the $G_{i}$ heterotrimeric $\mathrm{G}$ protein by ANCA IgG $\mathrm{F}\left(\mathrm{ab}^{\prime}\right)_{2}$ fragments is necessary but not sufficient to stimulate the recruitment of those downstream mediators used by intact ANCA IgG. J Am Soc Nephrol 2003;14:661-669.

15 Ben Smith A, Dove SK, Martin A, Wakelam MJ, Savage CO: Antineutrophil cytoplasm autoantibodies from patients with systemic vasculitis activate neutrophils through distinct signaling cascades: comparison with conventional $\mathrm{Fc}-\gamma$ receptor ligation. Blood 2001;98:1448-1455.

16 Kettritz R, Schreiber A, Luft FC, Haller H: Role of mitogen-activated protein kinases in activation of human neutrophils by antineutrophil cytoplasmic antibodies. J Am Soc Nephrol 2001;12:37-46.

17 Kettritz R, Choi M, Butt W, Rane M, Rolle S, Luft FC, Klein JB: Phosphatidylinositol 3-kinase controls antineutrophil cytoplasmic antibodies-induced respiratory burst in human neutrophils. J Am Soc Nephrol 2002;13: $1740-1749$.
8 Hewins P, Morgan MD, Holden N, Neil D, Williams JM, Savage CO, Harper L: IL-18 is upregulated in the kidney and primes neutrophil responsiveness in ANCA-associated vasculitis. Kidney Int 2006;69:605-615.

19 Reddy P: Interleukin-18: recent advances. Curr Opin Hematol 2004;11:405-410.

20 Moosig F, Csernok E, Kumanovics G, Gross WL: Opsonization of apoptotic neutrophils by anti-neutrophil cytoplasmic antibodies leads to enhanced uptake by macrophages and increased release of tumour necrosis factor- $\alpha$. Clin Exp Immunol 2000;122:499503.

21 Ewert BH, Becker ME, Jennette JC, Falk RJ: Antimyeloperoxidase antibodies induce neutrophil adherence to cultured human endothelial cells. Ren Fail 1995;17:125-133.

22 Haas M, Eustace JA: Immune complex deposits in ANCA-associated crescentic glomerulonephritis: a study of 126 cases. Kidney Int 2004;65:2145-2152.

23 Brouwer E, Huitema MG, Klok PA, de Weerd $\mathrm{H}$, Tervaert JW, Weening JJ, Kallenberg CG: Antimyeloperoxidase-associated proliferative glomerulonephritis: an animal model. J Exp Med 1993;177:905-914.

24 Yang JJ, Jennette JC, Falk RJ: Immune complex glomerulonephritis is induced in rats immunized with heterologous myeloperoxidase. Clin Exp Immunol 1994;97:466473.

-25 Heeringa P, Brouwer E, Klok PA, Huitema MG, Van Den Born J, Weening JJ, Kallenberg CG: Autoantibodies to myeloperoxidase aggravate mild anti-glomerular-basementmembrane-mediated glomerular injury in the rat. Am J Pathol 1996;149:1695-1706.

26 Xiao H, Heeringa P, Hu P, Liu Z, Zhao M, Aratani Y, Maeda N, Falk RJ, Jennette JC: Antineutrophil cytoplasmic autoantibodies specific for myeloperoxidase cause glomerulonephritis and vasculitis in mice. J Clin Invest 2002;110:955-963.

Renal Vasculitis? 
27 Little MA, Smyth CL, Yadav R, Ambrose L, Cook HT, Nourshargh S, Pusey CD: Antineutrophil cytoplasm antibodies directed against myeloperoxidase augment leukocyte-microvascular interactions in vivo. Blood 2005;106:2050-2058.

-28 Pfister H, Ollert M, Frohlich LF, Quintanilla-Martinez L, Colby TV, Specks U, Jenne DE: Antineutrophil cytoplasmic autoantibodies against the murine homolog of proteinase 3 (Wegener autoantigen) are pathogenic in vivo. Blood 2004;104:1411-1418.

-29 Franssen CF, Stegeman CA, Kallenberg CG, Gans RO, De Jong PE, Hoorntje SJ, Tervaert JW: Antiproteinase 3- and antimyeloperoxidase-associated vasculitis. Kidney Int 2000; 57:2195-2206.

- 30 Heeringa P, Van Den Born J, Brouwer E, Dolman KM, Klok PA, Huitema MG, Limburg PC, Bakker MA, Berden JH, Daha MR, Kallenberg CG: Elastase, but not proteinase 3 (Pr3), induces proteinuria associated with loss of glomerular basement membrane heparan sulphate after in vivo renal perfusion in rats. Clin Exp Immunol 1996;105:321-329.

- 31 Johnson RJ, Couser WG, Chi EY, Adler S, Klebanoff SJ: New mechanism for glomerular injury. Myeloperoxidase-hydrogen peroxide-halide system. J Clin Invest 1987;79: 1379-1387.

- 32 Yang JJ, Preston GA, Pendergraft WF, Segelmark M, Heeringa P, Hogan SL, Jennette JC, Falk RJ: Internalization of proteinase 3 is concomitant with endothelial cell apoptosis and internalization of myeloperoxidase with generation of intracellular oxidants. Am J Pathol 2001;158:581-592.
3 Huugen D, Xiao H, van Esch A, Falk RJ, Peutz-Kootstra CJ, Buurman WA, Tervaert JW, Jennette JC, Heeringa P: Aggravation of antimyeloperoxidase antibody-induced glomerulonephritis by bacterial lipopolysaccharide: role of tumor necrosis factor- $\alpha$. Am J Pathol 2005; 167:47-58.

34 Xiao H, Heeringa P, Liu Z, Huugen D, Hu P, Maeda N, Falk RJ, Jennette JC: The role of neutrophils in the induction of glomerulonephritis by antimyeloperoxidase antibodies. Am J Pathol 2005;167:39-45.

35 Lamprecht P: Offbalance: T-cells in antineutrophil cytoplasmic antibody-associated vasculitides. Clin Exp Immunol 2005; 141 : 201-210.

-36 Gutfleisch J, Baumert E, Wolff-Vorbeck G, Schlesier M, Strutz HJ, Peter HH: Increased expression of CD25 and adhesion molecules on peripheral blood lymphocytes of patients with Wegener's granulomatosis and ANCApositive vasculitides. Adv Exp Med Biol 1993;336:397-404.

37 Ludviksson BR, Sneller MC, Chua KS, TalarWilliams C, Langford CA, Ehrhardt RO, Fauci AS, Strober W: Active Wegener's granulomatosis is associated with HLA-DR ${ }^{+}$ $\mathrm{CD} 4^{+} \mathrm{T}$ cells exhibiting an unbalanced Th1type $\mathrm{T}$ cell cytokine pattern: reversal with IL-10. J Immunol 1998;160:3602-3609.
38 Moosig F, Csernok E, Wang G, Gross WL: Costimulatory molecules in Wegener's granulomatosis: lack of expression of CD28 and preferential up-regulation of its ligands B7-1 (CD80) and B7-2 (CD86) on T cells. Clin Exp Immunol 1998;114:113-118.

$>39$ Komocsi A, Lamprecht P, Csernok E, Mueller A, Holl-Ulrich K, Seitzer U, Moosig F, Schnabel A, Gross WL: Peripheral blood and granuloma $\mathrm{CD} 4{ }^{+} \mathrm{CD} 28^{-} \mathrm{T}$ cells are a major source of interferon- $\gamma$ and tumor necrosis factor- $\alpha$ in Wegener's granulomatosis. Am J Pathol 2002;160:1717-1724.

40 Lamprecht P, Moosig F, Csernok E, Seitzer U, Schnabel A, Mueller A, Gross WL: CD28negative $\mathrm{T}$ cells are enriched in granulomatous lesions of the respiratory tract in Wegener's granulomatosis. Thorax 2001;56: 751-757.

41 Brouwer E, Stegeman CA, Huitema MG, Limburg PC, Kallenberg CG: T-cell reactivity to proteinase 3 and myeloperoxidase in patients with Wegener's granulomatosis. Clin Exp Immunol 1994;98:448-453.

42 Griffith ME, Coulthart A, Pusey CD: T cell responses to myeloperoxidase and proteinase 3 in patients with systemic vasculitis. Clin Exp Immunol 1996;103:253-258.

43 Lawyer C, Henkle J, Bakir H: Nasal carriage of staphylococcal infection in Wegener granulomatosis. Ann Intern Med 1994;121:74-75.

44 Mayet WJ, Marker-Hermann E, Schlaak J, Meyer zum Buschenfelde KH: Irregular cytokine pattern of $\mathrm{CD} 4^{+} \mathrm{T}$ lymphocytes in response to Staphylococcus aureus in patients with Wegener's granulomatosis. Scand J Immunol 1999;49:585-594. 